Intervenção em Saúde do Trabalhador

Marcelo Firpo de Souza Porto (iD) https://orcid.org/0000-0002-9007-0584 Bruno Sena Martins ${ }^{b}$ (iD) https://orcid.org/0000-0003-3367-9155

a Fundação Oswaldo Cruz (Fiocruz), Escola Nacional de Saúde Pública Sérgio Arouca, Núcleo Ecologias, Epistemologias e Promoção Emancipatória da Saúde. Rio de Janeiro, RJ, Brasil.

b Universidade de Coimbra, Centro de Estudos Sociais. Coimbra, Portugal.

Contato:

Marcelo Porto

E-mail:

marcelo.firpo@ensp.fiocruz.br

Os autores declaram que não há conflitos de interesses.

Os autores informam que o trabalho não foi subvencionado, que não é baseado em tese e não foi apresentado em eventos científicos.

\section{Repensando alternativas em Saúde do Trabalhador em uma perspectiva emancipatória}

\author{
Rethinking alternatives in Worker's Health from an \\ emancipatory perspective
}

\section{Resumo}

Diante da gravidade da crise envolvendo graves retrocessos de políticas sociais em curso no Brasil, a proposta deste ensaio é pensar alternativas para futuras intervenções em Saúde do Trabalhador em uma perspectiva emancipatória. Trata-se de um convite à reflexão de novos horizontes teóricos e políticos que façam dialogar a Saúde do Trabalhador com os referenciais da abordagem pós-colonial e da proposição das Epistemologias do Sul (EdS). As EdS substanciam a obra do cientista social português Boaventura de Sousa Santos em torno de um pensamento alternativo de alternativas inspirado pelos saberes produzidos nas lutas sociais dos grupos subalternizados. Após apresentarmos uma síntese das EdS e do conceito de pensamento abissal, discutimos alguns limites e potencialidades para pensar novos horizontes teóricos, temáticos e políticos em trabalho e saúde. Em seguida refletimos sobre como os desastres industriais são emblemáticos por articular processos de exclusões radicais dentro e fora dos muros fabris. Por fim, discutimos a potência das EdS em abrir os termos do debate sobre possíveis intervenções em Saúde do Trabalhador, trazendo para o campo novos referenciais que fazem repensar, de forma ampla e radical, as agendas epistemológicas e políticas pela frente.

Palavras-chave: saúde do trabalhador; epistemologias do sul; abordagem pós-colonial; desastres industriais; pensamento abissal.

\begin{abstract}
In view of the severity of the Brazilian crisis involving serious setbacks in social policies, the purpose of this essay is to think alternatives for future interventions in Workers' Health from an emancipatory perspective. It is an invitation to reflect on new theoretical and political horizons for discussing Workers' Health from the reference of the postcolonial approach and the proposition of the Epistemologies of the South (EdS). The EdS reflects the work of the Portuguese social scientist Boaventura de Sousa Santos around an alternative thinking of alternatives inspired by knowledge produced in social struggles of the groups that were made subaltern. After presenting a synthesis of the EdS and the concept of abyssal thinking, we discuss some limits and potentialities for thinking new theoretical, thematical and political horizons in workers' health. Then we reflect on how industrial disasters are emblematic by articulating radical exclusion processes within and outside the factory walls. Finally, we discuss the potential of EdS to open the debate on possible interventions in Workers' Health, bringing new theoretical frameworks to the field, and enabling the broad and radical rethinking of the epistemological and political agendas to come.
\end{abstract}

Keywords: Worker's Health; Epistemologies of the South; post-colonial approach; industrial disasters; abyssal thinking. 


\section{Introdução: repensando o campo da saúde do trabalhador}

Autores como Mendes e Dias ${ }^{1}$ e Lacaz ${ }^{2}$ assumem a emergência da saúde do trabalhador como uma tentativa de ruptura e avanços com relação tanto à medicina do trabalho como à saúde ocupacional. Enquanto a primeira centraliza suas ações no papel dos médicos no controle da força de trabalho, a segunda reflete certo avanço das relações de trabalho nos países capitalistas centrais ao assumir a saúde sob um enfoque multi e interdisciplinar com a organização de equipes multiprofissionais, incluindo uma maior busca de integração entre os serviços médicos com a higiene e a segurança do trabalho, ou seja, uma maior dedicação ao tema preventivo e ao controle dos riscos ocupacionais.

Já a saúde do trabalhador, no contexto da redemocratização na América Latina nas décadas de 1970 e 1980, emerge influenciada pela chamada medicina social e, no Brasil, pela saúde coletiva. Suas origens e seus significados, contudo, são vistos de distintas maneiras. No texto mais referenciado no Brasil sobre a definição do campo, Mendes e Dias ${ }^{1}$ entendem a emergência da saúde do trabalhador como um movimento surgido nos países mais industrializados do mundo ocidental e difundido globalmente a partir dos anos 1960 e 1970. Destacam-se Alemanha, França, Inglaterra, Estados Unidos e particularmente Itália, cuja reforma sanitária e atuação sindical, a qual conformou o Modelo Operário Italiano (MOI) em saúde, inspiraram fortemente o Brasil. Consideramos essa visão de Mendes e Dias pouco crítica e eurocêntrica ao assumir a saúde do trabalhador como um avanço universal na humanização das relações de trabalho.

Numa leitura mais informada do contexto brasileiro e latino-americano, Lacaz ${ }^{2}$ defende que o surgimento do campo ocorre no Brasil no final dos anos 1970 com a consolidação e a militância do "novo sindicalismo" ligado ao proletariado urbano. A influência marxista da Medicina Social Latino-americana (MSLA) se concretiza na ideia de determinação social do processo saúde/doença e na centralidade do trabalho, marcada por autores como Laurell e Noriega ${ }^{3}$, no México, e por Breihl ${ }^{4}$, no Equador. Para Lacaz ${ }^{2}$, os reflexos da contribuição da MSLA na construção da saúde do trabalhador no Brasil são observados tanto na academia quanto nos serviços de saúde do Sistema Único de Saúde (SUS) em construção desde os anos 1980, com a crescente participação dos trabalhadores organizados em sindicatos, inaugurando um relacionamento mais democrático entre Estadosociedade. A reboque da $8^{\text {a }}$ Conferência Nacional de Saúde, talvez o principal marco de criação do campo tenha sido a realização da $1^{\text {a }}$ Conferência Nacional de Saúde dos Trabalhadores (CNST) em 1986, que ampliou a criação dos Programas de Saúde do Trabalhador (PSTs), iniciada em meados dos anos 1980, e diversas outras ações nos anos seguintes.

No período inicial de sua construção, a natureza das intervenções em saúde do trabalhador possuía, em articulação com a construção da chamada vigilância ${ }^{5}$, forte conexão com as origens da MSLA e da saúde coletiva, com um forte apelo aos processos de participação dos trabalhadores como proposto no $\mathrm{MOI}^{6}$, ou ainda na ergonomia ou ergologia de origem francesa $^{7}$. A ideia de participação ativa dos trabalhadores decorre de uma visão ampliada de saúde, que vai além da melhoria dos indicadores de morbimortalidade, e traduz-se na procura de redução e controle dos riscos e das cargas laborais presentes nos processos de trabalho que podem acarretar acidentes, doenças ou enfermidades diversas. Ela está fortemente relacionada ao significado de determinação social, por este implicar mudanças estruturais nas relações de poder que impeçam formas de exploração e alienação características das relações sociais de trabalho e de suas implicações sobre a saúde nas sociedades capitalistas, o que é agravado ainda mais na América Latina com sua inserção periférica na Divisão Internacional do Trabalho no sistema-mundo ${ }^{8}$. Portanto, haveria uma dinâmica marcante entre a capacidade de mobilização dos trabalhadores em direção a sociedades mais justas e democráticas para que as intervenções sobre as condições e situações de trabalho pudessem ser mais efetivas. Como sugerem Machado e Porto ${ }^{9}$, relações sociais de trabalho mais democráticas permitiriam valorizar mais a vida, o trabalho e a saúde do que o capital, substanciando-se no crescente desenvolvimento de políticas públicas, ações intersetoriais e coletivas de promoção da saúde voltadas às estratégias de transformação dos processos e ambientes de trabalho.

Passados cerca de 20 anos da $1^{\text {a }}$ CNST, um período marcado por governos neoliberais nos anos 1990 e pelo início da era do governo de coalização liderado pelo Partido dos Trabalhadores em 2003, Gomes e Lacaz ${ }^{10}$ publicaram um texto que reflete sobre três lacunas do campo: (i) a falta de uma Política Nacional de Saúde do Trabalhador; (ii) a fragmentação e dispersão da produção científica da área que não permitia a conexão entre agentes políticos, movimentos sociais, gestores e profissionais de saúde; (c) por fim, o enfraquecimento e a pouca capacidade de pressão dos movimentos sociais e dos trabalhadores.

Entre os mais de 12 anos do artigo de Gomes e Lacaz e o momento presente, em que pese alguns avanços pontuais e a publicação em 2012 da Política 
Nacional de Saúde do Trabalhador e da Trabalhadora, podemos constatar que muitas lacunas apontadas por Gomes e Lacaz permanecem. Mais grave, desde 2015 surgiram graves retrocessos no conjunto das políticas sociais em um contexto de profunda crise política e institucional marcada pelo impeachment da presidenta Dilma Rousseff, em 2016, e pela ascensão de um governo não eleito que passou a implementar uma agenda neoliberal ditada pelo "mercado" e pela mídia hegemônica conservadora.

Diante da gravidade da crise, que alternativas podemos pensar para o desenvolvimento de futuras intervenções em Saúde do Trabalhador em uma perspectiva emancipatória? A proposta deste manuscrito é um convite à reflexão de novos horizontes teóricos e políticos que possam dialogar com os referenciais da saúde do trabalhador a partir do que o cientista social português Boaventura de Sousa Santos denomina um pensamento alternativo de alternativas.

\section{Um pensamento alternativo de alternativas: as epistemologias do sul e a construção de sociedades pós-abissais}

Nas últimas décadas, tem ganhado relevância o trabalho de intelectuais e ativistas políticos que focam na Ásia, África e América Latina a partir de leituras ligadas à crítica do colonialismo e seus lega$\operatorname{dos}^{11}$. Esse olhar contesta a leitura da realidade produzida a partir do referencial moderno eurocêntrico, e cujas diferentes contribuições podem ser reunidas nos chamados estudos pós-coloniais. A releitura do capitalismo passa por processos coloniais-racistas que estão na base das clivagens econômicas, sociais e epistemológicas que, desde o final do século XV, forjaram o sistema mundo moderno. No contexto africano e asiático, em estreita relação com os movimentos independentistas anticoloniais que no século $\mathrm{XX}$ mudaram a face daqueles continentes, ganham relevo as visões críticas ao entendimento eurocêntrico do mundo, da justiça, do conhecimento e das hierarquias do humano. Surgem propostas como as avançadas pelo movimento da negritude, a partir de Aimé Cesaire e Léopold Sédar Senghor, pelos estudos subalternos que se desenvolveriam na Índia em torno da produção de uma história não imperial, ou o singular apelo da obra de Frantz Fanon à urgência de uma autodeterminação anticolonial e antirracista $^{12}$. O famoso livro de Fanon, Os condenados da Terra $^{13}$, foi escrito nos momentos finais de sua vida, encerrada precocemente aos 36 anos em 1961, e no Brasil seu legado influenciou a obra de Paulo Freire e outros intelectuais.
No âmbito da América Latina o programa de pesquisa denominado modernidade/colonialidade passou a influenciar o pensamento crítico na região a partir da virada do século XXI ${ }^{11}$. Diversos autores do pensamento latino-americano nas décadas anteriores contribuíram para sedimentar essa vertente, sejam os ligados à busca de uma ciência social autônoma e anti-imperialista, à teologia, ou aos teóricos da dependência e da filosofia da libertação. Dentre eles podemos lembrar o colombiano Orlando FalsBorda, o argentino Rodolfo Kusch, o mexicano Pablo González Casanova e os brasileiros Paulo Freire e Darcy Ribeiro. Dentre os autores mais influentes do grupo modernidade/colonialidade encontram-se o peruano Aníbal Quijano, recentemente falecido, o argentino radicado no México Enrique Dussel, o colombiano Arturo Escobar, e inúmeros outros. Segundo Escobar ${ }^{14}$, essa escola tem por base a crítica da modernidade e da globalização, assumidos como um fenômeno histórico, sociológico, cultural e filosófico universal e totalizante. Reconhece-se de que o fim das colônias na geopolítica mundial, iniciado nas Américas no final do século XVII e aparentemente encerrado no século XX no pós-guerra, não foi o fim do colonialismo ou, como diria o recentemente falecido Anibal Quijano, do "patrón mundial de poder capitalista eurocéntrico y colonial / moderno"15 (p. 373). A modernidade eurocêntrica é vista como uma visão particular de mundo que nega, desqualifica e invisibiliza outros sujeitos e concepções de mundo, natureza, economia, trabalho e formas de conhecimento. Esse o sentido do que se denomina colonialidade do saber e do poder, e seu enfrentamento implica um esforço teórico e político de descolonização - o que alguns chamam de giro decolonial - da produção teórica sobre a história, a cultura e as alternativas de sociedade que possam ser produzidos de forma mais autônoma pelas populações e seus movimentos sociais da América Latina, assim como em outros continentes. Há uma relação estratégica da dimensão epistemológica em sua relação com as lutas sociais em busca de uma nova razão decolonial ou pós-colonial, sendo realizada uma forte crítica à ciência moderna e ocidental ante seu papel nos processos de dominação e exclusão de outras alternativas de mundo e de saberes ${ }^{11}$.

Dentre os autores pós-coloniais destacamos as contribuições do cientista social português Boaventura de Sousa Santos. Ele possui uma vasta obra $^{16-23}$ que dialoga com autores e realidades da América Latina, África e Ásia, e há cerca de dez anos passou a ser reunida na proposição das Epistemologias do Sul (EdS). Estas são compreendidas como um amplo corpo teórico crítico, um pensamento alternativo de alternativas construído para enfrentar o pensamento único da modernidade eurocêntrica a partir de seu modo tricéfalo de dominação: 
o colonialismo, o capitalismo e o patriarcado. Estes se articulam de diferentes maneiras em diversos contextos e regióes, e a incapacidade de analisar articuladamente tais formas de dominação impedem as teorias críticas de avançar em uma compreensão mais ampla e no apoio às lutas emancipatórias de todos os oprimidos, sejam eles trabalhadores, indígenas, negros, camponeses, mulheres, integrantes da comunidade LGBTI, entre outros.

Para Santos ${ }^{20}$, as EdS são um conjunto de procedimentos que procuram reconhecer e validar os saberes nascidos da luta e produzidos pelos grupos sociais como forma de resistência contra as injustiças e opressões. Nesta concepção, o Sul deveria ser entendido como uma metáfora do sofrimento humano injusto causado pelo capitalismo, pelo colonialismo e pelo patriarcado. Assim como podemos pensar num Norte dentro do Sul, aquilo a que Santos em vários momentos chama "Sul Imperial", representado pelas elites que defendem o projeto moderno capitalista e colonial, haveria um Sul (ou vários Suis) dentro do Norte Global, o que estaria aliás a aumentar como decorrência da expansão do neoliberalismo, das migrações e do fascismo social nos países centrais do capitalismo.

Como o próprio nome reflete, a dimensão epistemológica, inseparável das dimensões política e ontológica, é considerada fundamental pelas EdS para a transformação social emancipatória. Esta é pensada como um horizonte pós-capitalista, pós-colonial e pós-patriarcal, que implica uma transição paradigmática a partir da valorização de sujeitos, saberes e alternativas de sociedade atualmente oprimidos e invisibilizados. Para isso é necessário construir as condições para um diálogo horizontal que valorize tanto a pluralidade interna da ciência moderna como aquilo que, por estar fora dela, foi desqualificado. Falamos da valorização da experiência do mundo (e não apenas da experimentação) que vivifica em saberes ancestrais de comunidades, nas lutas de populações e grupos organizados em processos de resistências - tais como as lutas de indígenas, afrodescendentes, camponeses, mulheres, favelados, LGBTI, dentre outros -, em articulação com o conjunto dos diversos trabalhadores explorados. Para Santos ${ }^{19}$, a construção do diálogo e dos critérios de validação de saberes legítimos é tarefa da ecologia de saberes.

A ideia de pensamento abissal e linha abissal constitui uma das propostas mais originais das Epistemologias do Sul ${ }^{19}$. Busca-se ir além da exploração dos trabalhadores para compreender formas de exclusão radical que desconsideram certas pessoas e povos do Sul Global da condição de humanos e sujeitos portadores de direitos e saberes. A linha abissal é "simultaneamente radical, invisível e invisibilizadora, e se encontra por detrás de fenômenos como o racismo, a xenofobia e outras formas de violência"11, uma linha que

impede a copresença do universo “deste lado da li-
nha” com o universo “do outro lado da linha”. Do lado
de lá, não estão os excluídos, mas os seres sub-huma-
nos não candidatos à inclusão social. A negação dessa
humanidade é essencial à constituição da modernida-
de, uma vez que é condição para que o lado de cá pos-
sa afirmar a sua universalidade. Assim, práticas que
não se encaixam nas teorias não põem em causa essas
teorias, e práticas desumanas não põem em causa os
princípios da humanidade ${ }^{22}$. (p. 16)

A ideia de pensamento abissal permite entender como podem existir diferentes formas de opressão em uma mesma região, um país, uma cidade ou mesmo um mesmo local de trabalho em função de duas realidades que convivem, o Norte e o Sul Global. O Norte Global moderno e eurocêntrico é representado pelos espaços em que o capitalismo globalizado expressa tanto seus benefícios como suas contradições mais visíveis, mas que podem dialeticamente institucionalizar conquistas, dos trabalhadores e cidadãos, decorrentes de suas lutas sociais. São os espaços do "lado de cá" da linha abissal pautados pelo conhecimento-regulação assente no tripé da ciência, do direito e do Estado modernos com suas instituições. Já o Sul Global, mais que um espaço geográfico, representa a metáfora do sofrimento humano das exclusões radicais. Nesses espaços as instituições que correspondem à modernidade (Estado-direitociência) dão lugar a formas de espoliação e violência sem a proteção das leis e do Estado, ainda que essas existam e é dito que sirvam a todos. As lutas sociais do Sul Global, por isso, precisam necessariamente ser anticoloniais e antipatriarcais a partir de resistências e alternativas que enfrentem essas formas de opressão, sendo por definição lutas que apontam para sociedades pós-coloniais e pós-abissais. Reconhece-se a importância da luta de classes, mas a negação das lutas sociais dos excluídos radicalmente marca um estruturalismo eurocêntrico, ainda que crítico, que deslegitima e aparta as lutas dos oprimidos do Sul Global. Esse é um dos problemas da academia crítica em países como Brasil, e "descolonizá-la" significa conectar questões ontológicas e epistemológicas às sociais.

A potência do pensamento abissal reside em uma compreensão ampla e complexa de como certos espaços fazem coabitar distintas lógicas: uma visível, a metropolitana que corresponde a certo estado de direito, e outra invisível marcada pela violência e espoliação que equivale ao Sul Global. Essa realidade está presente principalmente nos países periféricos ou semiperiféricos do sistema-mundo no capitalismo glo$\mathrm{bal}^{8}$. A crescente globalização produz níveis crescentes de complexidade, interseções e deslocamentos da linha abissal. De um lado o Sul Global avança na Europa, nos 
Estados Unidos da América e em países do centro capitalista, produzindo tendências para o fascismo social e a xenofobia. Ao mesmo tempo mantém-se um Norte "moderno" e colonial dentro dos países do Sul Global com histórico de colonialismo demarcado pela indiferença aprendida das elites e classes médias diante das violências que ocorrem, por vezes ao lado, nos grupos radicalmente excluídos pela linha abissal. Tal complexidade marca as dificuldades e os desafios de articulação entre o conjunto das lutas sociais empreendidas pelos vários sujeitos oprimidos. É também um abismo epistemológico na medida em que a suposta neutralidade e objetividade da ciência tende a excluir sujeitos e temas fundamentais para compreender e enfrentar diferentes opressões e violências que geram sofrimentos. Essas exclusões radicais marcam os vários racismos e discriminações que se tornam ainda mais complexos e invisíveis em contextos como o brasileiro, já que aparentemente a mestiçagem, nosso mito de uma sociedade multirracial e multiétnica, tende precisamente a encobrir exclusões radicais.

A sutileza e complexidade da abissalidade residem em como compreender a convivência contraditória entre realidades dos dois lados da linha, assim como das condições que permitem o cruzar das linhas. Pensemos em alguns exemplos de aparente reconhecimento e inclusão, mas que mantêm de diferentes formas o pensamento abissal. Para que um indígena tenha direitos é preciso deixar de ser indígena, ou então ser tutelado e viver de forma totalmente apartada como um grupo social exótico, similar aos ecossistemas e às espécies em risco de extinção. Para um negro ser incluído em uma sociedade multirracial, porém abissal, é necessário "branquear" ou negar sua negritude, rejeitar a religião de matriz africana, comportando-se e vestindo-se como seria de se esperar de uma pessoa "normal" sem demostrar sua origem africana ou expressar sua indignidade diante de séculos de escravidão. Para uma mulher, ainda que beneficiada pelas lutas feministas, permanecer no "lado de cá" da linha que cruzou torna necessário negar as lutas sociais de outros excluídos radicalmente, inclusive das mulheres pobres e negras. Como afirmam Cunha e Lauris ${ }^{24}$, no caso das mulheres um pensamento pós-abissal implicaria dar visibilidade às iniciativas de economia solidária e popular engendradas e lideradas por mulheres no Sul Global.

\section{Limites e alternativas para pensar novos horizontes para a saúde do trabalhador}

As Epistemologias do Sul (EdS), mais que receitas ou modelos de intervenção, propõem uma ampliação do pensamento crítico e nos inspiram a repensar questões de saúde e trabalho. Não se trata propriamente de um novo paradigma que exclui outros, mas sim de pensar desconstruções e possibilidades de novas construções que articulem lutas sociais e oportunidades de intervenções que questionem formas radicais de exclusão e invisibilidade. Esse é o objetivo da "sociologia das ausências"17, que busca tornar visíveis os temas e sujeitos que se encontram ausentes numa sociedade abissal, fortalecendo lutas sociais e a capacidade de agenciamento das populações radicalmente excluídas. Já a "sociologia das emergências" 17 analisa as alternativas em andamento que estejam construindo um futuro de possibilidades plurais e concretas, simultaneamente utópicas e realistas, a partir do que emerge no presente em movimentos que buscam quebrar monoculturas de saber e poder, formando as bases da transição civilizatória e paradigmática de uma sociedade pós abissal. Redefine-se assim o significado de emancipatório, pois libertar uma classe social ou um povo não deveria se dar à custa da continuidade de novas formas de opressão.

A partir dessa reflexão, comecemos por discutir algumas ausências que marcam a saúde do trabalhador no âmbito da saúde coletiva. Por exemplo, a tese de doutorado de Sergio Arouca ${ }^{25}$, grande intelectual do movimento sanitarista brasileiro, discute como o cuidado médico é central para a lógica capitalista, o controle da força de trabalho e a produção de mais-valia. A relação entre a expansão capitalista e a saúde é analisada por Arouca e outros intelectuais críticos da saúde a partir do crescimento do chamado complexo médico-industrial ou médico-financeiro, uma complexa rede na qual interagem setores, organizações e sistemas públicos e privados de saúde por meio de hospitais, ambulatórios e serviços de diagnósticos e de tratamento. Para Arouca ${ }^{25}$, o cuidado médico contribui para o aumento da produtividade, participa do aumento da mais-valia relativa, diminuindo o tempo de trabalho necessário, e pode contribuir para a criação da mais-valia absoluta na medida em que, mantendo o trabalhador em boas condições de saúde, torna possível a realização de jornadas extraordinárias de trabalho ${ }^{25}$.

Uma questão importante a ressaltar aqui diz respeito aos alicerces intelectuais e políticos da saúde coletiva construídos entre meados dos anos 1970 e o início dos anos 1990, com forte influência estruturalista e de cientistas sociais eurocêntricos. Embora em uma perspectiva crítica quanto ao papel da biomedicina no capitalismo, tais alicerces não questionam o papel colonial ou racista da medicina científica e da ciência moderna em geral, consideradas conhecimentos superiores que precisam ser preservados nas lutas emancipatórias. A crítica feita ao paradigma da 
história natural da doença, pautada por uma cadeia causal de hábitos, costumes, valores, idades, sexos, raças e aspectos psicológicos que levam à doença, resultou na determinação social - ampliando, sem negar, as bases da biomedicina a partir do materialismo histórico. Nesse sentido, a ciência deveria servir à classe trabalhadora, mas sua base epistemológica de caráter universal não implicaria uma crítica ontológica mais ampla para rever, por exemplo, o significado da violência contra negros, indígenas, camponeses e mulheres.

Tal perspectiva eurocêntrica foi marcante na própria trajetória da Associação Brasileira de Saúde Coletiva (Abrasco), criada em 1979, e no peso que a epidemiologia, ainda que denominada social, possui na organização do campo. Na já mencionada tese de Arouca $^{25}$ são citados inúmeros autores europeus e norte-americanos, principalmente estruturalistas, mas poucos brasileiros ou latino-americanos, com a ausência de figuras importantes no pensamento pós-colonial, como Darcy Ribeiro, Paulo Freire ou Orlando Fals-Borda. Questões acerca das populações indígenas, negras e quilombolas não são mencionadas na discussão em torno do dilema preventivista, e os camponeses são citados por Arouca apenas acerca das barricadas na Alemanha em 1848, nas quais suas associações lutavam por assistência médica e medicamentos. Entre os pensadores mais heterodoxos, Arouca menciona dois autores posteriormente relevantes na articulação teórica da saúde com os estudos pós-coloniais e as EdS: Ivan Illich, que influenciou a luta contra a medicalização ${ }^{26}$; e Franco Basaglia, este sim com forte influência na área de saúde mental e na luta antimanicomial ${ }^{27}$, movimentos de grande importância para a questão da humanização e dos direitos humanos na saúde.

Outra área a mencionar é saúde e ambiente, com diversos autores provenientes da saúde do trabalhador que incorporam referenciais pós-coloniais ${ }^{11,28-29}$. Ao se aproximarem dos territórios e movimentos sociais do campo, das florestas e águas, envolvendo camponeses, pequenos agricultores, quilombolas, pescadores tradicionais, indígenas e outros, tornou-se claro que as lutas sociais não podiam ser mais compreendidas exclusivamente a partir do paradigma estruturalista e do conflito capital-trabalho que marcou a compreensão inicial da determinação social da saúde e da área de saúde do trabalhador. Daí a aproximação com a ecologia de saberes.

Não se trata de deixar de reconhecer a relevância das lutas contra as formas de exploração dos trabalhadores por diversos setores econômicos. O que é colocado em xeque pelos sujeitos sociais antes invisibilizados é o próprio sentido de saúde, natureza, trabalho e desenvolvimento, bem como o direito de que outras formas de ser, saber e atuar possam ser reconhecidas e valorizadas na construção de sociedades pós-capitalistas e pós-coloniais. Tais questionamentos apontam alternativas que constituem objetos da "sociologia das emergências", por exemplo, por meio da construção de uma agricultura camponesa e agroecológica que repense o conceito de natureza, de alimentação, trabalho das mulheres, conhecimento das plantas no cuidado da saúde e de economia solidária sobre como os alimentos são produzidos, distribuídos e comercializados. Eles também apontam para a articulação com os movimentos que apostam na agricultura urbana e outras formas mais justas, ecológicas e saudáveis de relação campo-cidades. De forma similar, as lutas de indígenas, quilombolas e outras populações, além das lutas das mulheres, levantam inúmeras possibilidades de produção de conhecimentos, construção de alternativas e articulação entre lutas por saúde, dignidade e direitos territoriais.

\section{Pensamento abissal e desastres: articulando exclusões radicais dentro e fora dos muros fabris}

Existem várias possibilidades de se pensar possíveis articulações entre as EdS e a Saúde do Trabalhador, a começar pela incorporação dos saberes situados dos trabalhadores no $\mathrm{MOI}^{2,6}$ ou ainda a ergologia ${ }^{7}$ que também assume questões de gênero. Nessa seção destacaremos o tema dos desastres industriais para repensar possibilidades e alternativas sobre diagnósticos e intervenções de saúde e trabalho, principalmente a partir das propostas de pensamento abissal e da sociologia das ausências.

O histórico desastre ocorrido em 1984 na comunidade de Vila Socó, localizada na cidade de Cubatão em São Paulo, é exemplar, pois concretiza a ideia de pensamento abissal e as exclusões e violências radicais propostos pelas EdS. Este trágico desastre, tão pouco lembrado na história dos acidentes industriais no Brasil e no mundo, ocorreu após o vazamento de gasolina de um duto da empresa Petrobrás junto a uma favela em Cubatão, no estado de São Paulo. A comunidade rapidamente foi consumida por chamas algum tempo após as pessoas começarem a armazenar gasolina em suas casas. Embora o número oficial de mortos na época tenha sido 93, estimativas indicam a morte de mais de 500 pessoas $^{30}$. O nível de exclusão dessas pessoas era tão radical que nem com as próprias mortes as vítimas tiveram o direito de serem reconhecidas. Permaneceram inexistentes e invisibilizadas como eram em vida, um exemplo trágico da condição de vulnerabilidade social que viviam. Ainda que esse conceito tenha sido importante para ampliar o referencial teórico dos desastres, 
consideramos muito limitado para, mais que entender, expressar com indignação o que estava em jogo. A vulnerabilidade social, ainda que complexa ${ }^{31}$, é uma teoria nascida de uma razão fria para analisar e se posicionar contra uma realidade que diz respeito à dignidade humana. $\mathrm{E}$ a indignação exige, como nos lembra Boaventura, uma razão quente.

A partir da perspectiva das EdS e do pensamento abissal, Martins ${ }^{32}$ realizou um estudo etnográfico 30 anos após o desastre de Bhopal. Para ele, o desastre testemunha o poder colonial-capitalista que desqualifica o valor da vida, seja nos milhares de mortos, mas também nos sobreviventes que permanecem afetados e resistem em suas lutas por dignidade. A partir da proposta de pensamento abissal, Martins ${ }^{32}$ propõe a ideia de uma memória pós-abissal capaz de expressar a violência colonial por entre "corpos e violências, mortos e sobreviventes, reconhecendo, como promessa de novos saberes, o tempo testemunhado por aqueles que melhor conheceram os escombros da modernidade" 32 (p. 146). Seria interessante reconstruir a memória abissal de Vila Socó, o desastre industrial mais importante do Brasil em termos de mortes imediatas.

Podemos pensar a relação entre linha abissal e desastres industriais nos países do Sul Global, com paralelos para outros problemas de ecologia urbana em sua relação com as desigualdades socioambientais. Por exemplo, existe uma linha abissal entre os muros das fábricas que dividem os territórios por onde circulam trabalhadores com contratos de trabalho daqueles que moram e transitam ao redor das fábricas em condições precárias, ou seja, as populações que vivem em regiões poluídas e sem saneamento básico. Bullard ${ }^{33}$ denominou tais áreas de "zonas de sacrifício", moradias próximas a lixões industriais poluentes e perigosas. Nelas vivem populações negras e discriminadas, confinadas socialmente em guetos, análogos às favelas. Nas metrópoles subalternas do Sul Global existe uma forte confluência entre a geografia política das desigualdades socioespaciais com o conceito de linha abissal, não apenas no fenômeno dos desastres, mas com todo um conjunto de questões que envolvem saúde e ecologia. Por exemplo, o fim e o início de diversas infraestruturas sanitárias, como a coleta de lixo, os canos de água potável e de esgotamento sanitário, ou mesmo do transporte digno entre locais de moradia e o trabalho, todas essas fronteiras demarcam as zonas de cidadania e não cidadania, dos direitos humanos e dos não direitos dos sacrificados.

No caso de Bhopal, a linha abissal se torna evidente quando analisamos as medidas preventivas antes, durante e após o acidente ${ }^{34}$, uma espécie de gestão abissal dos riscos que assenta em padrões radicalmente distintos. O espaço fabril é sujeito a regras de segurança mais bem definidas pelas instituições de governo e pela cultura técnica das empresas - principalmente as químicas, que lidam com substâncias perigosas. A solução planejada para evitar que o tanque em Bhopal explodisse foi simplesmente o rompimento de uma válvula de "segurança" que conduziu os gases tóxicos para fora dos muros fabris por meio de tubulações que os dispersaram para fora e longe da fábrica. Essa "medida preventiva" abissal fez com que a nuvem tóxica com uma substância inodora e incolor alcançasse em plena madrugada as casas precárias ao redor da fábrica. As pessoas foram pegas de surpresa e mais de duas mil morreram asfixiadas nos momentos seguintes, inclusive as que chegaram a ser atendidas pelas unidades de saúde, pois os profissionais destas jamais tinham tido capacitação para lidar com aquela emergência e não faziam a menor ideia de como proceder e quais antídotos usar ${ }^{35}$.

Contudo, nem sempre a linha abissal pode ser definida com precisão no Sul Global. A dicotomia abissal tende a se complexificar à medida que detalhamos o intercruzamento e a superposição de processos de inclusão e exclusão de direitos com lógicas metropolitanas e abissais. Nesses casos, a invisibilidade tende a se acentuar pela dificuldade de estabelecer contornos espaciais ou relacionais precisos dos processos de segregação e discriminação. Tal complexidade exige uma forma mais fractal e menos linearmente dicotômica de pensar racismos e violências. Por exemplo, os trabalhadores de inúmeras fábricas brasileiras possuem simultaneamente um estatuto metropolitano e abissal, são simultaneamente sujeitos e não sujeitos. Alguns são terceirizados e precarizados, trabalhando no mesmo setor que os trabalhadores diretos com contratos mais estáveis e com melhor remuneração, outros são negros ou nordestinos e sofrem múltiplas e distintas discriminações, assim como as mulheres trabalhadoras, ou ainda trabalhadores que se assumem homossexuais ou transexuais.

A própria divisão institucional brasileira no âmbito governamental espelha um tipo de pensamento abissal: os órgãos de "meio ambiente", responsáveis pelo controle da poluição que sai "para fora" das fábricas, baseiam-se em padrões diferenciados, mais preocupados com o "verde", a ecologia sem humanos, do que com as populações próximas das áreas poluídas - via de regra habitantes do "lado de lá" da linha abissal. Os padrões dos órgãos de segurança e saúde do trabalho tendem a ser muito mais rígidos que os padrões ambientais gerais, sendo os especialistas do meio ambiente mais preocupados com os ecossistemas, as espécies vegetais e animais, anestesiados por não enxergar os "sub-humanos" que habitam espaços ao redor de lixões e fábricas. 


\section{Considerações inacabadas: articulando lutas e alternativas de intervenção}

Ao longo deste trabalho buscamos mostrar como abordagens pós-coloniais e as Epistemologias do Sul podem contribuir com novas formas de olhar e, com isso, nos ajudar a descontruir, reconstruir, ampliar e reinventar questões sobre saúde, trabalho e possibilidades de intervenções. Como se trata de um artigo limitado para questões tão amplas, nosso papel tem caráter mais introdutório e reflexivo, e não explorador das inúmeras possibilidades de articulações teóricas e práticas abertas ao longo do texto.

Talvez a principal contribuição proposta por nós seja a de ressignificar o caráter emancipatório das intervenções em saúde e trabalho. Consideramos que as restringir aos muros das fábricas, aos trabalhadores formais e suas lutas contra as formas de exploração pelo capitalismo não nos ajudará muito a compreender e transformar os grandes desafios impostos pela atual globalização hegemônica. A lógica desta cada vez mais mercantiliza e "coisifica" a vida e a saúde, capturando o Estado, o direito e as instituições públicas, inclusive as universidades, para uma lógica excludente e fragmentadora. Fazem isso em nome do progresso, da ciência, da democracia, da liberdade (principalmente de imprensa) e até dos direitos humanos "universais", concebidos para vigorar apenas do lado privilegiado da linha abissal nas sociedades metropolitanas.

Vemos como principal contribuição teórica e política dos estudos pós-coloniais e das EdS a articulação necessária entre as lutas da classe trabalhadora com o conjunto dos excluídos radicalmente em sua condição de humanos portadores de direitos e saberes. O capitalismo e o fascismo social crescem quando os excluídos são colocados como vítimas e colocam-se uns contra os outros. Por exemplo, trabalhadores que defendem seus empregos versus moradores ao redor das fábricas que lutam pela saúde e contra a contaminação química; homens que assumem postos de trabalho e são dirigentes sindicais versus mulheres trabalhadoras e sindicalistas que lutam contra o machismo; movimentos sociais e urbanos de classe média ou mesmo populares que discutem segurança pública e a questão das drogas sem considerar as condições e lutas dos movimentos de favelas contra a violência policial e das milícias; os movimentos rurais que lutam pela reforma agrária e contra a agricultura capitalista versus indígenas e quilombolas que lutam por demarcação e reconhecimento; trabalhadores petroleiros e movimentos sociais que lutam por uma Petrobrás pública que defende as riquezas nacionais versus ambientalistas e populações tradicionais que lutam contra a contaminação química, o aquecimento global e a destruição dos ecossistemas.

Os grupos sociais radicalmente excluídos, como indígenas, negros, camponeses e mulheres, não enfrentarão injustiças, apenas políticas "universais" de inclusão que buscam eliminar a pobreza e reduzir desigualdades a partir de políticas distributivas. $\mathrm{O}$ "direito ao desenvolvimento" vira uma armadilha ao não ser questionado como gerador, ele próprio, de inúmeras violências, como o epistemicídio. A realidade mostra que o desenvolvimento econômico e as políticas públicas focadas apenas na defesa de interesses específicos, ainda que legítimos, pode servir à lógica da fragmentação e da manipulação hegemônica.

O aumento da intolerância e da violência em suas múltiplas facetas - econômica, simbólica, de gênero, cultural, religiosa - parece crescer não apenas no Brasil: trata-se de um fenômeno atual que atinge tanto o Sul Global como os países mais ricos e poderosos do Norte Global. Por isso precisamos de referenciais teóricos que repensem a democracia, unam as várias lutas e reconheçam as infinitas possibilidades ontológicas e epistemológicas de humanidade que possibilitem a convivência com dignidade dos vários povos, grupos sociais e culturas. Isso ocorrerá a partir dos processos de luta em que haja um efetivo diálogo intercultural entre eles para o desenvolvimento de ações políticas articuladas que rompam barreiras entre os oprimidos. Por isso que temas como as justiças sanitária e global precisam caminhar juntas com as justiças ambiental e cognitiva. Por exemplo, atualmente a violência cresce em várias cidades brasileiras quando policiais, milícias, narcotráfico e grupos evangélicos fundamentalistas se unem contra pais e mães de santo nas favelas.

Os exemplos dos desastres de Vila Socó, em Cubatão, e Bhopal, na Índia, mostram como a saúde dos trabalhadores não é pensável sem uma análise mais ampla da exploração capitalista-colonial da modernidade ou das linhas abissais que definem as hierarquias do humano. Não podemos reduzir o número de vítimas de catástrofes-crimes como em Cubatão, e recentemente em Mariana, Minas Gerais, sem que a proteção aos trabalhadores formais se articule com as diversas lutas contra exclusões radicais que atualmente atingem terceirizados, moradores de favelas, camponeses, quilombolas, pescadores artesanais e indígenas que vivem nesses territórios. Certamente existem inúmeras possibilidades de explorar novas articulações e fronteiras a partir de movimentos e lutas sociais que permitam questionar e repensar os conceitos de saúde, trabalho e intervenção.

Não se trata propriamente de colocar questões pontuais e identitárias relacionadas ao como 
enfrentar diferentes formas de violência relacionadas ao mundo do trabalho, seja contra os negros, as mulheres ou contra os membros das comunidades LGBTI. A falta de articulação de tais lutas é incentivada por certas visões pós-modernas fragmentárias e alienadoras para, na medida em que essas lutas são reconhecidas, simultaneamente são reenquadradas para fortalecer o pensamento abissal que não critica as verdades do pensamento único. Dessa forma o capitalismo e a economia de mercado deixam de ser questionados, assim como a ciência e as tecnologias que servem ao "progresso". O desafio que se coloca, portanto, é como articular tais questões com as lutas anticapitalistas, anticoloniais e antipatriarcais mais amplas, impedindo que as lutas contra as violências e as violações de direitos humanos se transformem em demandas pontuais fragmentadas e alienantes.

Na realidade a brasileira, a dinâmica entre o Norte Global (o "deste lado") e o Sul Global (o "lado de lá") é intensa, complexa e faz parte da própria história da constituição de nossa sociedade e nossos territórios, assim como os latino-americanos formados em processos de "independência" subalternizados aos interesses coloniais e imperiais. Há guetos e racismos, mas ao mesmo tempo também existem inúmeras formas de convivências e de cruzar linhas que precisariam ser melhor compreendidas e analisadas para que questões sobre saúde, trabalho e ecologia possam ser repensadas
- sejam elas os desastres industriais, as condições de vida e trabalho de certas populações e territórios ou inúmeras outras situações reconhecidas como de injustiça ambiental, por vezes expressas em lutas de resistência ao redor de conflitos denominados pela ecologia política de conflitos ecológicos ou ambientais ${ }^{36}$. Sair dos guetos e pensar projetos emancipatórios mais amplos é uma contribuição real das EdS, sejam eles nos espaços micro ou macroutópicos, já que a transescalaridade dessas articulações é um dos maiores desafios para uma globalização contra-hegemônica.

Em relação à reinvenção das intervenções em saúde e trabalho, o momento atual de crise talvez seja propício para retomarmos iniciativas que quebrem muros e articulem os espaços especificamente do mundo do trabalho formal com os outros espaços cidadãos. Por exemplo, das lutas de favelados e trabalhadores sem teto por uma cidade inclusiva; das mulheres e comunidade LGBTI para serem respeitados; dos camponeses e sem-terra pela agroecologia e por uma produção de alimentos saudáveis comercializados em feiras que unam solidariamente produtores e consumidores na construção de outros mercados; dos indígenas e quilombolas para terem reconhecidas suas cosmovisões que podem inspirar a todos e todas. Tais espaços e lutas podem nos ajudar a repensar conceitos como natureza, saúde, trabalho, novas economias, respeito e solidariedade.

\section{Contribuições de autoria}

Ambos os autores contribuíram substancialmente para o artigo; o primeiro autor foi definido nesta posição por conhecer mais efetivamente a realidade brasileira.

\section{Referências}

1. Mendes R, Dias EC. Da medicina do trabalho à saúde do trabalhador. Rev Saúde Púb. 1991;25:341-9.

2. Lacaz F. Saúde do trabalhador: um estudo sobre as formações discursivas da academia, dos serviços e do movimento sindical [tese de doutorado]. Campinas: Universidade Estadual de Campinas; 1996.

3. Laurell AC, Noriega M. Processo de produção e saúde: trabalho e desgaste operário. São Paulo: Hucitec; 1989.

4. Breilh J. Epidemiología crítica: ciencia emancipadora e interculturalidad. Buenos Aires: Lugar Editorial; 2003.

5. Machado IMH. Processo de vigilância em saúde do trabalhador. Cad Saúde Pública. 1997;13(Suppl 2):33-45.

6. Lacaz FAC. O campo da saúde do trabalhador: resgatando conhecimentos e práticas sobre as relações trabalho-saúde. Cad Saúde Pública. 2007;23(4):757-66.

7. Brito J. Saúde do trabalhador: reflexões a partir da abordagem ergológica. In: Figueiredo M, Athayde M, Brito J, Alvarez, D, organizadores. Labirintos do trabalho: interrogações e olhares sobre o trabalho vivo. Rio de Janeiro: DP\&A; 2004. p. 91-114.

8. Wallerstein I. Globalization or the age of transition? a long-term view of the trajectory of the worldsystem. Intern Sociol. 2000;15(2):249-65.

9. Machado JMH, Porto MFS. Promoção da saúde e intersetorialidade: a experiência da vigilância em saúde do trabalhador na construção de redes. Epidemiol Serv Saúde. 2003;12:121-30.

10. Gomez CM, Lacaz FAC. Saúde do trabalhador: novas-velhas questões. Ciênc Saúde Coletiva. 2005;10:797-807. 
11. Porto MF. Pode a vigilância em saúde ser emancipatória? um pensamento alternativo de alternativas em tempos de crise. Ciênc Saúde Coletiva. 2017;22(10):3149-59.

12. Meneses MP, Martins BS, organizadores. As guerras de libertação e os sonhos coloniais: alianças secretas, mapas imaginados. Coimbra: Almedina; 2013.

13. Fanon F. Os condenados da Terra. Juiz de Fora: Editora da UFJF; 2005.

14. Escobar A. worlds and knowledges otherwise: the Latin America modernity/coloniality research program. Cult Studies. 2007;21(2-3):179-210.

15. Quijano A. Colonialidad del poder y classificacion social. J World Syst Res. 2000;6(2):342-86.

16. Santos BS. A crítica da razão indolente: contra o desperdício da experiência. São Paulo: Cortez, 2002.

17. Santos BS. Para uma sociologia das ausências e uma sociologia das emergências. Rev Crit Ciênc Soc. 2002;63:237-80.

18. Santos BS. A gramática do tempo: para uma nova cultura política. São Paulo: Cortez; 2006.

19. Santos BS. Para além do pensamento abissal: das linhas globais a uma ecologia de saberes. Novos Estud Cebrap. 2007;79:71-94.

20. Santos BS. O direito dos oprimidos. São Paulo: Cortez; 2014.

21. Santos BS. Epistemologies of the south: justice against epistemicide. Boulder: Paradigm; 2014.

22. Santos BS, Araújo S, Baumgarten M. As epistemologias do sul num mundo fora do mapa. Sociologias. 2016;18(43):14-23.

23. Santos BS, Meneses MP. Epistemologias do sul. 2a. ed. Coimbra: Almedina; 2014.

24. Cunha, T, Lauris É. À procura de um outro constitucionalismo económico: construindo a cidadania a partir de iniciativas de economia solidária e popular lideradas por mulheres do sul. Sociologias. 2016;18(43):150-75.
25. Arouca ASS. O dilema preventivista: contribuição para a compreensão da medicina preventiva [tese de doutorado]. Campinas: Universidade Estadual de Campinas; 1975.

26. Nogueira RP. A segunda crítica social da saúde de Ivan Illich. Interface Comunic Saúde Educ. 2003;7(12):185-90.

27. Amarante P. Loucos pela vida: a trajetória da reforma psiquiátrica no Brasil. Rio de Janeiro: Editora Fiocruz; 2001.

28. Rigotto $\mathrm{RM}$ et al. O verde da economia no campo: desafios à pesquisa e às políticas públicas para a promoção da saúde no avanço da modernização agrícola. Ciênc Saúde Coletiva. 2012;17(6):1533-42.

29. Carneiro FF, Rigotto RM, Augusto LGS, Friedrich K, Búrigo AC, organizadores. Dossiê Abrasco: um alerta sobre os impactos dos agrotóxicos na saúde. Rio de Janeiro: EPSJV; 2015.

30. Freitas CM, Porto MFS, Gomes CM. Acidentes químicos ampliados: um desafio para a saúde pública. Rev Saúde Pública. 1995;29(6):503-14.

31. Porto MFS. Complexidade, processos de vulnerabilização e justiça ambiental: um ensaio de epistemologia política. Rev Crit Ciênc Soc. 2011;93:31-58.

32. Martins BS. Revisitando o desastre de Bhopal: os tempos da violência e as latitudes da memória. Sociologias. 2016;18(43):116-48.

33. Bullard RD. The quest for environmental justice: human rights, and the politics of pollution. San Francisco: Sierra Club; 2005.

34. Porto MFS, Freitas, C M. Major chemical accidents in industrializing countries: the socio-political amplification of risk. Risk Anal. 1996;16:19-29.

35. Freitas CM, Porto MFS, Machado JMH, organizadores. Acidentes industriais ampliados: desafios e perspectivas para o controle e a prevenção. Rio de Janeiro: Editora Fiocruz; 2000.

36. Porto MF, Pacheco T, Leroy JP. Injustiça ambiental e saúde no Brasil: o mapa de conflitos. Rio de Janeiro: Editora Fiocruz; 2013. 